\title{
Reducionismo e o experimento mental da duplicação humana
}

\section{Reductionism and the human duplication thought-experiment}

\section{Osvaldo Pessoa Júnior}

Professor do Departamento de Filosofia, FFLCH, Universidade de São Paulo (USP), São Paulo, SP - Brasil, e-mail: opessoa@usp.br

\section{Resumo}

Examina-se o experimento mental da duplicação humana, apontando-se diferentes posições com relação aos resultados possíveis do experimento. Uma primeira posição defende a superveniência, quer da perspectiva reducionista, quer da emergentista, visões essas que são comparadas. Certos aspectos morais do experimento mental são então considerados, especialmente em relação à ideia da morte. Tomando-se então o reducionismo como hipótese de trabalho, sugerem-se duas possibilidades para a investigação do problema difícil dos qualia: a postulação de algum novo tipo de interação física, e a postulação de uma contraintuitiva lei de escala. Uma possibilidade deste último caso levaria a uma violação da superveniência.

Palavras-chave: Materialismo. Reducionismo. Emergentismo. Qualia. Lei de escala. 


\section{Abstract}

The human duplication thought-experiment is examined, and basic positions concerning the possible outcomes of the experiment are spelled out. A first position sustains supervenience, either from a reductionist or an emergentist perspective, and such views are contrasted. Certain moral aspects of the thought-experiment are then considered, especially in relation to the idea of death. Taking reductionism as a working hypothesis, two possibilities are suggested for investigating the hard problem of qualia: the postulation of some novel sort of physical interaction, and the postulation of a counterintuitive law of scaling. One possibility for the latter would lead to a violation of supervenience.

Keywords: Materialism. Reductionism. Emergentism. Qualia. Scaling law.

\section{Experimento mental da duplicação humana}

Experimentos mentais (Gedankenexperimenten) em metafísica não permitem que se tirem quaisquer conclusões a respeito do mundo real, ${ }^{1}$ mas são uma estratégia interessante para definir certos conceitos filosóficos de maneira mais precisa.

Consideremos o seguinte experimento mental, típico de ficção científica, ${ }^{2}$ que envolve a criação de uma cópia material exata de uma pessoa. Esta situação é praticamente a mesma que o "novo teletransportador de escaneamento" explorado por Derek Parfit (1984, p. 199-201) em sua discussão sobre identidade pessoal.

A pessoa a ser copiada será chamada Ana-1, e sua cópia, Ana-2, é construída ao se recriar quase instantaneamente cada molécula de Ana-1, de tal forma que o estado de cada réplica de molécula é o mesmo que o da molécula original em Ana-1, e todas as relações espaciais (e de outros tipos)

1 Pode haver exceções a esta regra, no caso em que o objeto de estudo é o próprio pensamento.

2 Por exemplo, o filme $O 6^{\circ}$ Dia (The 6th Day), de 2000, protagonizado por Arnold Schwarzenegger e dirigido por Roger Spottiswoode. 
entre as moléculas de Ana-2 são as mesmas que as relações entre as moléculas de Ana- $1 .^{3}$

Quando a reprodução acontece, Ana-1 e Ana-2 encontram-se em ambientes perfeitamente semelhantes, de forma que nos primeiros instantes seus estados materiais permanecerão perfeitamente semelhantes, pelo menos descendo até a escala molecular. Após alguns instantes, porém, os dois sistemas começariam a rumar em direções diferentes, ou por causa das flutuações inevitavelmente diferentes em cada ambiente, ou porque a natureza não é determinística (ou os dois).

Eis então o arranjo do experimento mental. A primeira pergunta a ser feita é se Ana-2 teria consciência, ou se ela seria apenas um "zumbi". Materialistas diriam que ela é consciente, já que a consciência seria fruto apenas da matéria, ao passo que dualistas afirmariam que algo mais seria necessário para Ana-2 ter uma alma.

Supondo que Ana-2 tivesse consciência, a segunda pergunta a ser feita concerne à natureza dos estados mentais de Ana-1 e Ana-2 no instante da reprodução. As duas teriam pensamentos perfeitamente semelhantes, os mesmos sonhos, emoções, veriam exatamente as mesmas cores ou estariam prestando atenção aos mesmos cheiros?

A tese de que suas consciências seriam perfeitamente semelhantes é compartilhada por um amplo subconjunto do materialismo, cuja caracterização esboçaremos a seguir.

\section{Materialismo e superveniência}

Materialismo, ou fisicalismo, é a visão segundo a qual o que chamamos de alma, espírito, mente ou consciência é um produto apenas de processos materiais, e que compreende que na morte do corpo a mente de fato desaparece (a não ser que ela possa ser duplicada, como no experimento mental).

3 A rigor, tal cópia exata é proibida pelos teoremas de impossibilidade de clonagem da mecânica quântica, mas tal proibição não parece estar relacionada com a essência da consciência. Numa perspectiva alternativa, poder-se-ia estipular que se trate de uma cópia clássica ao nível molecular, o que pressupõe que efeitos de "descoerência", que surgem do banho térmico de movimento browniano em torno da molécula, borrariam qualquer coerência quântica entre partes das macromoléculas. Neste caso, diferenças submoleculares entre Ana-1 e Ana-2 seriam inevitáveis. 
Em sua acepção mais ampla, o materialismo não está comprometido com a tese de que a "matéria" seja a substância fundamental do Universo, mas está comprometido com a tese de que as entidades fundamentais do Universo (sejam elas partículas, campos, energia, cordas, o que quer que seja) são inanimadas, sem terem propósito ou outros atributos mentais. Evito também o termo "fisicalismo" porque as leis fundamentais da cosmovisão materialista também incluem princípios da química, da biologia (como a seleção natural) e de outras ciências naturais. O termo também é evitado para não fomentar qualquer rivalidade entre disciplinas científicas, com relação a qual seria a mais importante.

O materialismo tem uma longa história, começando com o atomismo greco-romano e a escola carvaka da Índia Antiga (LANGE, 1974; PESSOA Jr., 2006). Dos seus dois grandes problemas, um deles, o problema da perfeição da vida, encontrou solução adequada com a teoria da evolução biológica, mas o problema de explicar como a consciência surge a partir da matéria permanece sem solução.

$\mathrm{O}$ atomismo e a maior parte do materialismo do século XIX tendiam a ser reducionistas, no sentido de que o comportamento de um ser vivo (por exemplo) era concebido como se originando de maneira completa do comportamento de seus componentes microscópicos. Após 1970, no entanto, o projeto de desenvolvimento de versões não reducionistas do fisicalismo tornou-se dominante na literatura de filosofia da mente, e tais visões são geralmente rotuladas de emergentistas.

Robert Van Gulick (2001, p. 3) apresenta uma interessante classificação de posições reducionistas e emergentistas. O sentido de redução que nos interessa aqui é o que ele chama de reducionismo ontológico, que é distinto do reducionismo representacional (ou epistemológico). Das posições ontológicas que aceitam a redução dos estados e propriedades mentais a estados e propriedades materiais, todas aceitam que os estados mentais "supervenham" sobre certo domínio material, seja este o cérebro, todo o corpo, ou mesmo um eu estendido que incluiria partes do ambiente

A superveniência envolve a tese de que qualquer alteração no nível superior (como um estado mental) pressupõe uma alteração no nível inferior (o nível material, geralmente envolvendo a escala microscópica dos neurônios e células glia, ou mesmo a escala "nanoscópica" das moléculas). Ou, alternativamente, a tese de que se um estado de nível inferior não se altera, então o nível superior também permanecerá o mesmo. Esta última condição é exatamente o que é explorado no experimento mental da duplicação humana. A tese 
de que Ana-1 e Ana-2 têm propriedades mentais ou experiências subjetivas perfeitamente semelhantes é uma consequência da tese da superveniência do mental sobre os estados materiais do corpo humano.

\section{Reducionismo e emergentismo superveniente}

O emergentismo surgiu como uma reação à tendência "constritiva $\mathrm{e}$ autoritária" da redução (KIM, 2006, p. 547) e é usualmente definida como a tese geral de que, quando a matéria adquire um certo grau de complexidade, aparecem propriedades genuinamente novas, que não estão presentes em cada uma das partes separadas do todo. O que conta como "genuinamente novo" é objeto de muito debate, e o reducionista aceita de bom grado que propriedades macroscópicas como a elasticidade ou "ser algo molhado" [wetness] só podem surgir como propriedades coletivas em sistemas complexos. O que o reducionista defende, no entanto, é que elasticidade ou ser molhado são o reflexo de propriedades moleculares nanoscópicas, e que se tais propriedades mudarem para um número significativo de moléculas compondo o todo, então as propriedades macroscópicas associadas à elasticidade ou a ser molhado também mudariam. ${ }^{4}$ Reducionistas e emergentistas podem não discordar em casos de emergência "fraca", como os da física e química: a discordância é grande quando casos "fortes" são considerados, como a emergência da vida e da consciência (STEPHAN, 2002).

Parte da dificuldade de tradução entre os dois paradigmas do reducionismo e do emergentismo está no estatuto atribuído à noção de forma, arranjo, organização, ordem, estrutura ou conjunto de relações. Reducionistas ontológicos tendem a pensar em um pernilongo, por exemplo, como um número imenso de moléculas organizadas de tal maneira a produzir o típico comportamento do inseto, sendo, é claro, que a origem dessa organização é estabelecida pela evolução biológica. Essa organização é vista como a maneira pela qual a redução ontológica ocorre. Alguns emergentistas ontológicos, contudo, tendem a ver tal organização como um princípio não material,

4 Em certas condições, conhecidas na termodinâmica como "fenômenos críticos", uma mesma "classe de universalidade" congrega sistemas com diferentes composições nanoscópicas mas que exibem o mesmo comportamento macroscópico. Para o reducionista, este é um caso em que as relações entre as moléculas são bem mais importantes do que o estado individual de cada molécula (ver parágrafo seguinte).

Rev. Filos., Aurora, Curitiba, v. 22, n. 30, p. 69-81, jan./jun. 2010 
distinto dos elementos físicos do universo, de forma que a redução completa à matéria não poderia ser verdadeira.

A posição emergentista que aceita a superveniência de estados mentais a estados materiais deve concordar com o reducionista com relação aos prognósticos dados para o experimento mental da duplicação humana: Ana-1 e Ana-2 teriam, no instante da reprodução, estados mentais e experiências subjetivas perfeitamente semelhantes. Há, porém, duas variedades de emergentismo superveniente: com causação descendente e sem ela.

A causação descendente, na filosofia da mente, é a tese de que estados emergentes, como o desejo de tomar um sorvete de chocolate, podem afetar causalmente os estados materiais microscópicos do cérebro (levandonos à sorveteria), sem que haja uma conexão causal microscópica relevante. Se o materialismo reducionista for adotado como hipótese de trabalho, a causação descendente não faz nenhum sentido, já que a alegada conexão causal do nível superior sempre pode ser reduzida a uma conexão causal microscópica. Este é basicamente o argumento que Kim (2006, p. 558) apresenta contra a causação descendente. A única maneira de dar algum sentido ao conceito seria se houvesse uma violação da superveniência, conforme consideraremos na seção 7 .

Por outro lado, o emergentismo superveniente sem causação descendente é muito semelhante ao reducionismo. Ele pode ser caracterizado como uma versão "fenomenalista" (instrumentalista) do realismo reducionista: dado que na prática não se pode dar os detalhes da "reconstrução" (ANDERSON, 1972) dos fenômenos macroscópicos a partir dos estados nanoscópicos, seria então sem sentido (de acordo com o fenomenalista) defender uma redução ôntica do mundo macro à escala nano. Por outro lado, o reducionismo pode ser visto como uma tentativa de completar a teoria emergentista superveniente.

$\mathrm{O}$ reducionista reconhece que, na prática, uma redução completa e detalhada é impossível, mas defende que se houvesse um "demônio escalar" (semelhante ao demônio de Laplace) que tivesse acesso a toda informação relativa à escala nanoscópica do Universo, ele poderia prever corretamente o comportamento macroscópico de um pernilongo (PESSOA Jr., 2005). ${ }^{5}$

5 Nota-se, por sinal, que um reducionista escalar (que defende que o macro se reduz onticamente ao nano) pode também ser um holista (em oposição a um "separabilista"), se ele defender que o comportamento do pernilongo supervém a uma região material extensa (que pode ser o corpo do pernilongo, ou este e seu ambiente, ou mesmo todo o Universo), mas que esta região não pode ser analisada em partes separadas, se o demônio escalar for fazer uma previsão macroscópica correta.

Rev. Filos., Aurora, Curitiba, v. 22, n. 30, p. 69-81, jan./jun. 2010 


\section{Dilemas morais no experimento mental}

Retornando ao experimento mental da duplicação humana, suponha que, para realizar o experimento, os organizadores tivessem oferecido a Ana-1 uma grande quantia de dinheiro, digamos $\mathrm{R} \$ 2$ milhões, para que uma semana depois do processo de reprodução perfeita ela tivesse que ser morta, de maneira indolor, enquanto a sua cópia permanaceria viva, ocupando seu lugar no mundo. Ana-1 deveria aceitar a oferta?

Se Ana-1 fosse uma materialista reducionista de corpo e alma, ela não teria porque recusar a proposta. Do seu ponto de vista, no instante da duplicação, sua consciência é perfeitamente semelhante à de Ana-2. Após este instante inicial, Ana-2 poderia ser considerada uma contrapartida sua em um "mundo possível" (já que ela, Ana-1, poderia ter sido colocada nas circunstâncias ambientais em que Ana-2 se encontrou logo após a duplicação).

Ana-1 e Ana-2 são "indivíduos" distintos, no sentido de que os processos causais infligidos em uma delas não afeta a outra. Materialmente, ambas são (por construção) perfeitamente semelhantes, descendo até a escala molecular. Ou seja, ambos os indivíduos compartilham os mesmos tipos de moléculas (mas, é claro, não as mesmas instanciações, ou tokens), que estão organizadas (estruturadas) em arranjos perfeitamente semelhantes (pode-se dizer que cada conjunto de moléculas compartilham da mesma forma, desprezando-se as relações com o ambiente). Em outras palavras, os dois indivíduos são "qualitativamente idênticos", mas não "numericamente idênticos" (PARFIT, 1984, p. 201).

O que pode ser dito sobre suas consciências? O materialista reducionista concordaria com a afirmação de que "suas consciências são perfeitamente semelhantes" no instante da duplicação, mesmo se tratando de indivíduos numericamente distintos. $\mathrm{O}$ emergentista superveniente também deveria concordar com isso, mesmo que ele defenda a causação descendente (que só agiria em instantes posteriores).

Se este é o caso, então para Ana-1 não há diferença se é ela quem continua vivendo ou se é Ana-2. A conclusão é que não devemos temer a morte, se houver uma cópia perfeita de nós zanzando por aí. Agora que Ana-1 se convenceu, racionalmente, que não deve temer a morte, que diferença faz para ela se a cópia existente é exatamente igual a ela, ou se a cópia é só parcialmente semelhante a ela? Por que temer a morte, se há outras pessoas perambulando por aí, compartilhando muitos de nossos atributos?

Rev. Filos., Aurora, Curitiba, v. 22, n. 30, p. 69-81, jan./jun. 2010 
Qual é a causa de nosso medo da morte? Seria o fato de a morte ser terrível? A causa parece estar relacionada com a seleção natural. Considere um ancestral remoto do ser humano, por exemplo, o procônsul que viveu na África há 20 milhões de anos. Suponha que certo indivíduo procônsul nascesse com uma mutação genética, e não tivesse medo da morte. Ele teria tido uma probabilidade muito maior de ser devorado por um predador, de forma que seus alelos destemidos não seriam herdados por outros procônsules. $\mathrm{O}$ pavor da morte é altamente adaptativo! É por isso que a nossa própria morte parece tão terrível para nós. Mas isso não constitui motivo racional para temer a morte, e a decisão de Ana-1 de se deixar matar parece perfeitamente justificável de um ponto de vista materialista: não haveria uma alma ou essência individual que a distinguisse de Ana-2.

\section{Materialismo reducionista e qualia}

Se há um consenso nos debates envolvendo o materialismo, é que não há uma explicação materialista satisfatória para a consciência ou, para restringir um pouco a questão, não há uma teoria de como as qualidades subjetivas, ou qualia, surgem da matéria. Reducionistas, porém, tendem a ser otimistas sobre uma possível explicação para os qualia. Afinal de contas, um ser humano nada mais é, ontologicamente, do que octilhões de átomos interagindo de maneiras específicas; então deveria ser possível fazer um esboço de uma explicação reducionista da consciência. Uma defesa recente e já clássica desta abordagem é "hipótese surpreendente" (astonishing hypothesis) de Francis Crick (1994), que parece afirmar que um relato reducionista da consciência seria possível no estado atual de nosso conhecimento científico: tudo o que estaria faltando seria um modelo detalhado e adequado.

No entanto, é intuitivamente difícil conceber como esse programa conseguiria escapar do argumento simples de Leibniz em La Monadologie, $\S 17$, contra uma explicação mecanicista da consciência. É verdade que nosso cérebro não é constituído simplesmente de partes em movimento, como o gênio de Leipzig supôs em seu argumento, mas envolve interações eletromagnéticas, que ainda não foram adequadamente entendidas em termos das chamadas "qualidades primárias". Além disso, ligações químicas covalentes responsáveis pela composição de moléculas envolvem emaranhamento quântico (interações de troca). Assim, nossa ontologia física é muito mais rica do que a filosofia mecânica da época de Leibniz. Mesmo assim, não temos

Rev. Filos., Aurora, Curitiba, v. 22, n. 30, p. 69-81, jan./jun. 2010 
nenhuma pista de como nossas teorias físicas quantitativas podem tratar qualidades subjetivas.

Tomando o materialismo reducionista como hipótese de trabalho, mas rejeitando a solução de Crick, somos levados a explorar como nossa atual visão de mundo científica pode ser estendida para explicar a origem dos qualia. Este, é claro, é um dos problemas "difíceis" da consciência (CHALMERS, 1996), tentar cobrir o "fosso explicativo" (explanatory gap) entre processos físicos e consciência (LEVINE, 1983).

Parece haver pelo menos duas direções a serem exploradas: 1) a postulação de interações moleculares muito fracas de um tipo novo, e/ou 2) o estabelecimento de uma nova teoria de escala dos fenômenos nano para os macro.

Como guia para tal pesquisa, um princípio que pode ser usado é que nossa intuição pode falhar em domínios aos quais não tivemos acesso durante a evolução. A ciência moderna tem dado exemplos de semelhante fracasso nos domínios do muito pequeno (física quântica), do muito veloz (relatividade restrita), do muito massivo (relatividade geral), do muito frio (condensados quânticos), etc. É de se esperar que um fracasso semelhante possa ocorrer no domínio do muito complexo, e isso pode incluir nossas intuições simplistas sobre como propriedades escalam do domínio nano para o macro.

Uma teoria materialista dos qualia deveria fazer uma previsão sobre quais cores são percebidas por pombos, por exemplo, que possuem um sistema visual mais refinado do que o nosso, e também sobre como é ser um morcego, subjetivamente. Ela deveria estipular, de maneira geral, quais são as classes possíveis de qualia que qualquer ser sentiente poderia experienciar, mesmo que tais previsões teóricas não possam ser verificadas, devido a razões epistemológicas fundamentais.

\section{Um novo tipo de interação física}

Tomando o reducionismo como hipótese de trabalho, uma primeira direção que se pode tomar é a possibilidade de que um novo princípio ou lei da natureza possa estar em jogo. Esta não é uma ideia original, e na literatura mais recente ela foi discutida por David Chalmers (1996), com seu novo conjunto de "leis psicofísicas". Esse novo tipo de interação física teria que ser muito fraca ao nível molecular, mas em sistemas organizados de maneira complexa, envolvendo um número imenso de moléculas, tal 
interação seria amplificada e de alguma maneira resultaria em nossas sensações subjetivas.

Duas condições devem ser especificadas: $i$ ) a existência de uma interação muito fraca ao nível molecular; e $i i$ ) uma organização adequada do sistema de muitos corpos. O panpsiquismo clássico, como o de Leibniz, que atribui consciência ou percepção a todos os corpos da naturzea, não requereria a condição $i$.

O cérebro é um sistema material no qual diferentes espécies de qualia (cores, cheiros, emoções) surgem a partir dos mesmos tipos básicos de componentes materiais. O que faz uma espécie de quale diferente de outra parece estar relacionado à organização detalhada do cérebro (condição ii), mas também poderia estar relacionado com espécies diferentes de moléculas envolvidas (ou seja, a condição $i$ poderia variar entre tipos diferentes de moléculas).

Mas que tipo de interação física poderia levar a essas diferenças entre os qualia? Reconhece-se amplamente que a física clássica, com sua expressão quantitativa da natureza, não pode dar conta da existência de qualidades subjetivas. A física quântica tem despertado a imaginação de pensadores com orientação mística, devido a seu holismo e ao envolvimento do observador na descrição da natureza, mas ela ainda assim é uma descrição quantitativa da natureza. Além disso, não está claro como o holismo quântico (não localidade) poderia ser essencial para uma explicação reducionista dos qualia.

Uma sugestão feita na literatura filosófica, desde Brentano, é que o que estaria faltando nas leis físicas atuais, subjacentes ao fenômeno da mente, seria a noção de "intencionalidade" ou "sobredade" (aboutness). Mas mesmo no quadro da visão mecanicista da natureza, típico da cibernética clássica, a maior parte dos casos de propósito ou intenção de um agente consciente pode ser explicada supondo que este "representa" o ambiente e a si mesmo. Robôs que parecem agir com propósitos já foram construídos (está claro, porém, que eles no fundo agem de acordo com as intenções dos seus construtores humanos), então não parece haver nada de misterioso com nossas intenções no que concerne à comida, calor e afeto. Mesmo assim, poderia ser interessante explorar como uma noção de sobredade (aboutness) pode ser incorporada em uma lei física ou psicofísica, e se com isso seria possível tratar a "qualitatividade".

A explicação sugerida por Crick para sustentar sua "hipótese surpreendente" envolve frequências de oscilação de disparos neuronais no cérebro. Parece haver um consenso de que oscilações ou fenômenos ondulatórios são 
essenciais para a consciência humana, então parece plausível que este suposto novo princípio de qualitatividade deva incluir frequências de oscilação, que também são essenciais para a física quântica.

\section{Emergentismo não superveniente}

Argumentamos, na seção 5, que é razoável supor que nossas intuições possam falhar no domínio do muito complexo, e isso pode incluir nossas intuições simplistas sobre como propriedades "escalam" do pequeno para o grande. Se for verdade que não temos uma intuição adequada sobre as leis de escala, isso pode servir de apoio para certa crítica emergentista do reducionismo.

O emergentismo superveniente sem causação descendente, conforme apresentado na seção 3, não parece filosoficamente interessante: ele seria apenas uma versão fenomênica do reducionismo estrito (no sentido de ser antirrealista com relação à transição detalhada das escalas inferiores para as superiores). Para torná-la interessante, alguns autores introduziram o conceito de causação descendente, mas da perspectiva reducionista esta noção não faz muito sentido, a não ser que seja acoplada a uma negação da superveniência estrita. Introduzamos agora esta última posição, à luz do nosso experimento mental.

O emergentismo não superveniente é a posição materialista que afirmaria que Ana-1 e Ana-2 não possuem consciências perfeitamente semelhantes, mesmo que elas sejam (por hipótese) perfeitamente semelhantes em termos de moléculas e suas relações espaciais (e supondo também que os ambientes circundantes seriam perfeitamente semelhantes até a escala molecular). Em outras palavras, mesmo que ambas sejam perfeitamente semelhantes no instante da duplicação, elas poderiam ter propriedades emergentes diferentes neste instante inicial. Isso é contraintuitivo, mas como argumentamos anteriormente, nossas intuições poderiam falhar em domínios inacessíveis à experiência.

Para esclarecer essa posição, pode-se traçar uma analogia entre a causalidade e o reducionismo escalar (PESSOA Jr., 2005). A causalidade envolve a relação de determinação que ocorre entre eventos na dimensão temporal. Pode-se considerar que a escala espacial (comprimentos nano, micro, macro) é análoga à dimensão temporal, e que há uma relação de determinação entre (o análogo de) eventos em diferentes escalas. Tal relação pode ser chamada 
de "redução escalar-espacial". A redução escalar-espacial estrita (de escalas inferiores para superiores) é análoga ao determinismo estrito (do passado para o futuro). O que o emergentismo não superveniente defenderia é que a relação entre escalas espaciais inferior e superior é análoga a uma relação temporal indeterminista (intrinsecamente estocástica ou "tiquista").

A violação da superveniência poderia ocorrer na passagem da escala nanoscópica para a macroscópica, ou apenas na passagem do reino material para o mental. Esta última alternativa seria um caso de antimaterialismo, no sentido de que o mental não é completamente determinado pelo material.

Da perspectiva materialista, seria interessante investigar a primeira alternativa, a passagem do pequeno para o grande. O debate parece análogo àquele entre determinismo estrito e tiquismo, que se refere à natureza do Universo físico, mas não é decidível por meio de experimentos científicos (sendo, assim, um problema metafísico). A diferença é que o "tiquismo escalar"que seria a negação da superveniência estrita - é ainda mais contraintuitivo do que o tiquismo temporal (com o qual nos acostumamos após um século de física quântica).

\section{Conclusão}

O ponto de partida deste artigo foi o experimento mental da duplicação humana. Do ponto de vista materialista, as diferentes previsões a respeito dos resultados do experimento não separam reducionistas e emergentistas, mas supervenientistas (incluindo todos os reducionistas e um subconjunto dos emergentistas) e não supervenientistas. Extraímos também algumas considerações morais com respeito ao nosso medo da morte. Com relação à árdua tarefa de resolver o difícil problema de explicar os qualia de uma perspectiva materialista, duas sugestões heurísticas foram fornecidas. Uma envolve a postulação de algum tipo novo de interação física, possivelmente relacionado com o eletromagnetismo. A outra envolve uma revisão de nossa concepção a respeito da passagem da escala nano para a macro, incluindo a possibilidade de uma contraintuitiva violação da superveniência. O autor não acredita nesta última possibilidade, mas no contexto da descoberta é mais importante gerar novas ideias, analogias e soluções do que simplesmente justificar e defender posições preconcebidas. 


\section{Referências}

ANDERSON, P. W. More is different. Science, v. 177, n. 4047, p. 393-396, 1972.

CHALMERS, D. J. The conscious mind. Oxford: Oxford University Press, 1996.

CRICK, F. The astonishing hypothesis. New York: Scribner's, 1994.

KIM, J. Emergence: core ideas and issues. Synthese, v. 151, p. 547-559, 2006.

LANGE, F. A. The history of materialism. New York: Arno Press, 1974. Originalmente publicado em 1866.

LEVINE, J. Materialism and qualia: the explanatory gap. Pacific Philosophical Quarterly, v. 64, p. 354-361, 1983.

PARFIT, D. Reasons and persons. Oxford: Oxford University Press, 1984.

PESSOA Jr., O. Fisicalismo redutivo e sondas epistemológicas. In: ENCONTRO DA REDE PARANAENSE DE PESQUISA EM HISTÓRIA E FILOSOFIA DA CIÊNCIA, 3., 2005,Curitiba. Anais... Curitiba: SCHLA/UFPR, Curitiba, 2005. p. 179-190.

. O dogmatismo científico de tradição materialista. In: SILVA, C. C. (Org.). Estudos de história e filosofia das ciências. São Paulo: Livraria da Física, 2006. p. 41-57.

STEPHAN, A. Emergence, irreducibility, and downward causation. Grazer Philosophische Studien, v. 65, p. 77-93, 2002.

THE 6th Day. Director: Roger Spottiswoode. Los Angeles: Phoenix Pictures, 2000. 1 DVD (123 min.), Son., Color.

Van GULICK, R. Reduction, emergence, and other recent options on the mind/body problem: a philosophic overview. Journal of Consciousness Studies, v. 8, n. 9/10, p. 1-34, 2001.

Recebido: $15 / 03 / 2010$

Received: 03/15/2010

Aprovado: 05/05/2010

Approved: 05/05/2010 